\title{
Determination of the Mechanical Properties of Red Blood Cells in Sickle Cell Disease
}

\author{
Georges Minatchy 1*, Laurence Romana 1, Grégory Francius2 and Marc Romana3
}

1 Groupe de Technologie des Surfaces et des Interfaces - Université des Antilles - 97159 Pointe à

Pitre - Guadeloupe - France - French West Indies

2 LCPME - UMR 7564, 405 rue de Vandoeuvre, F-54600 Villers-lès-Nancy, France

3 UMR S_1134, Université des Antilles, Pointe-à-Pitre, F-97100 France, F-97100, France - French

West Indies

*Corresponding author :georges.minatchy@univ-antilles.fr

Sickle cell disease (SCD), the most frequent genetic disease in the West Indies and in France, is caused by the abnormal sickle hemoglobin ( $\mathrm{HbS}$ ) resulting from the substitution of an acid glutamic by a valine at codon 6 of the beta globin chain. Polymerization of deoxygenated $\mathrm{HbS}$ induces formation of long stiff rod-like fibers which force the red blood cells to take over a wide variety of irregular shape. SCD patients exhibit complications such as vaso-occlusion events due to the loss of red blood cell (RBC) deformability, and increase of RBC adherence to endothelial cells [1].

In the present study, the mechanical properties of the red blood cells are investigated by atomic force microscopy. For this purpose, the cells are immobilized on glass lamella coated with poly-L-lisine in order to increase RBC adherence. All the experiments are performed in presence of phosphate buffered saline. Red blood cells were imaged with silicon nitride probe with nominal spring constant of 0.06 $\mathrm{N} / \mathrm{m}$ whereas the mechanical measurements were performed with silicon tips colloidal particle with nominal spring constant of $0.035 \mathrm{~N} / \mathrm{m}$. More than 150 mechanical tests have been performed on each sample in order to have reliable statistical data. Four different patient groups were analyzed, AA, AS, SS and SS under hydroxyurea treatment. For each group, four individuals have been studied in order to evaluate intra-group variability. The data were statistically analyzed using a non-parametric ANOVA Kruskal-Wallis test. According to this statistical method the differences between groups will be considered if the probability value $\mathrm{p}$ is lower than 0.005. All force/deformation curves were analyzed with PUNIAS (Protein Unfolding and Nano-Indentation Analysis Software), a custom-built semi-automatic processing and analysis software. To calculate the Young modulus, we used Sneddon's modification of the Hertz model for the elastic indentation of a flat and soft sample by a stiff sphere [2].

AFM topographic images of AA and SS red blood cells are shown in figure1. Biconcave shape of the AA red blood cell is evidenced (Figure 1a) whereas falciform shape can be observed for red blood cell issued from SS patients (Figure 1b). Histograms of the Young's modulus recorded on the four different patient groups are reported in Figure 2. The statistical analyses of these data confirm a significant difference between blood cell elasticity of the different groups except for SS and AS groups. The comparison of the Young modulus medium values, $12.2 \mathrm{kPa}$ and $14.5 \mathrm{kPa}$ respectively for AA and AS group, allows us to conclude that AA red blood cells (Figure 2a) are less stiff than SS cells (Figure 2b) as expected. We also observed a decrease of the Young modulus for SS patients treated with hydroxyurea (Young modulus medium value is $7.8 \mathrm{kPa}$, Figure 2c) confirming the treatment efficiency. These results are partially different from those recorded on similar red blood cells using ektacytrometry technic [3-7]. Different mechanical solicitations of the cell using nanoindentation or ektacytometry are probably responsible of this discrepancy. 


\section{ACKNOLEDGEMENT}

The authors would like to thanks the Fond Social Européen and La Région Guadeloupe for their financial support.

\section{REFERENCES}

[1] J. L. Maciaszek et al., J. Strain Anal. Eng. Des. 46(5) (2011), p. 368.

[2] P. Carl et al., Pflugers Arch - Eur J Physiol 457(2) (2008), p. 551.

[3] M. Girasole et al., Micron. 43(12) (2012), p. 1273.

[4] N. Yeow et al., Adv Colloid Interface Sci. 249 (2017), p.1 49.

[5] G. Ciasca, et al.. Nanoscale 7(40) (2015), p. 17030.

[6] P. Connes et al., Blood Rev. 30(2) (2016), p. 111.

[7] N.Lemonne et al., Haematologica. 100(10) (2015), p. e383.
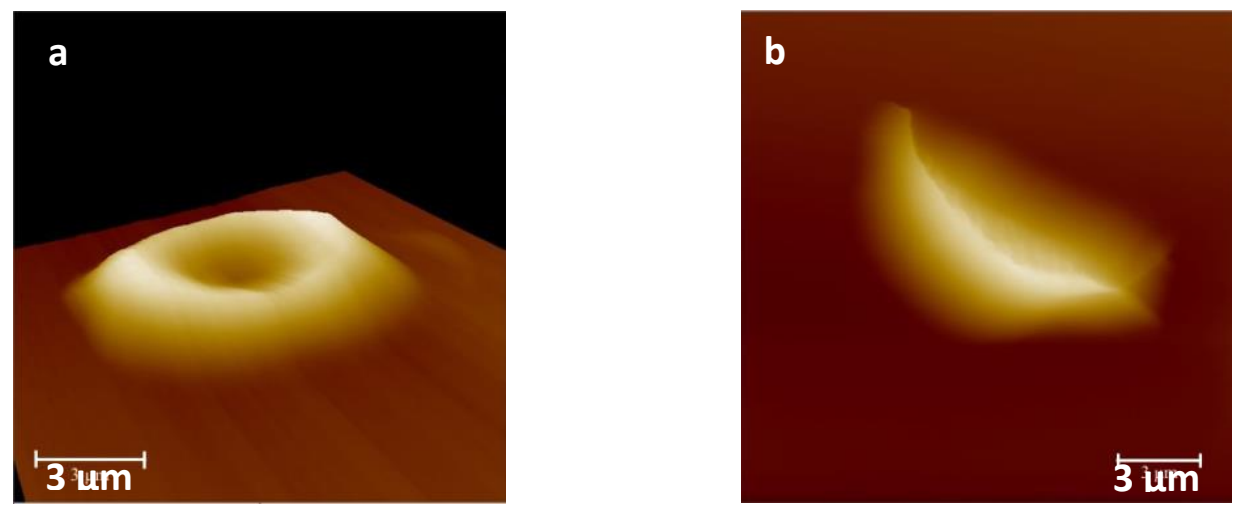

Figure 1. AFM topographic images of a) AA and b) SS red blood cells
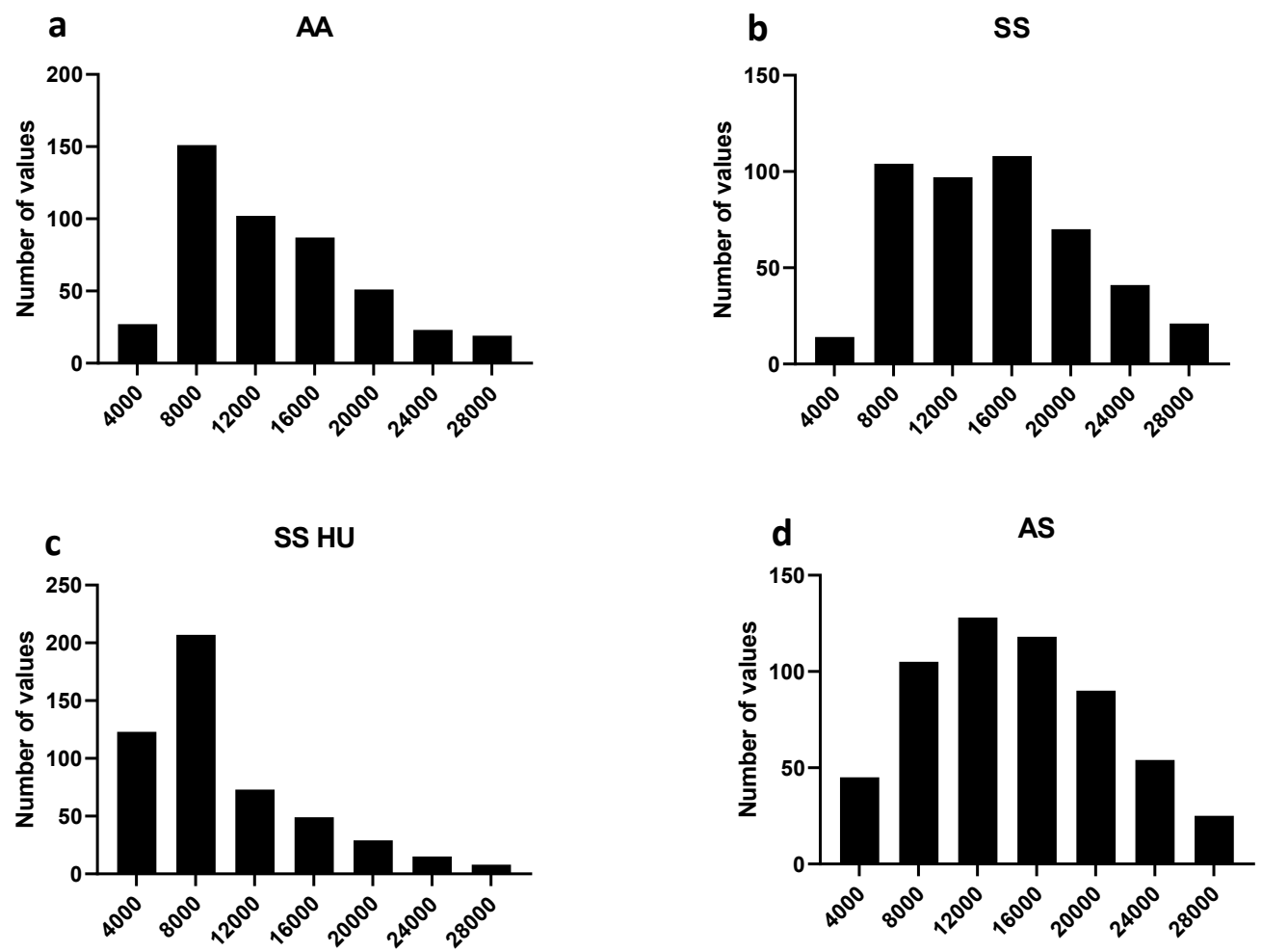

Figure 2. Young's modulus histograms of red blood cells issued from the four groups, AA, SS, SS + hydroxyurea and AS. 